\title{
Physical Properties of the Poly(1-olefin)s. Thermal Behavior and Dilute Solution Properties.
}

\author{
Jeou-shyong WANG, ${ }^{*}$ Roger S. Porter, ${ }^{* *}$ and Jack R. KNOX*** \\ * Monsanto Company, Pensacola, Florida, U.S.A. \\ **Polymer Science and Engineering, Materials Research Laboratory, \\ University of Massachusetts, Amherst, Massachusetts, U.S.A. \\ ***Amoco Chemicals Corporation, Naperville, Illinois, U.S.A.
}

(Received February 27, 1978)

\begin{abstract}
Poly(1-olefin)s from poly(1-butene) up to poly(1-octadecene) have been characterized. The melting point was measured by Differential Scanning Calorimetry (DSC1B) and dilatometry, the specific volume and volume expansion coefficient by dilatometry, and the unperturbed chain dimension by intrinsic viscosity at near theta conditions. A trend is confirmed for melting points and revealed for expansion coefficients of first a decrease with increasing side-chain length in the polyolefins, followed by an increase with further increase in length. The minimum is near poly(1-hexene) and poly(1-heptene). The specific volume of the poly(1-olefin) series exhibits a maximum around this same composition. The minima in melting point and thermal expansion coefficient and the maximum in specific volume are discussed in terms of chain-to-chain packing density. It is suggested that packing density is a minimum in this region. Two melting points were found for each of several higher poly(1olefin)s from poly(1-tridecene) up to poly(1-octadecene). It is found that the theta temperatures of the poly(1-olefin) series, as measured in two solvents, anisole and cyclohexanone, exhibit a minimum at poly(1-pentene). However, the characteristic ratios and the steric factors increase with increasing side-chain length for the entire series of measured poly(1olefin)s.
\end{abstract}

KEY WORDS Poly(1-olefin)s / Dilatometry / Calorimetry / Theta Temperatures / Solutions / Crystallinity / Solubility /

The thermal behavior and dilute solution properties for the lower members of the poly(1-olefin) series, i.e., polyethylene, polypropylene, and poly(1-butene), have been studied intensively. Only widely-scattered and uncorrelated studies on the properties of the higher members of the series have so far been published. ${ }^{1-17}$ The melting and glass transition temperatures of the poly(1-olefin) series have been measured by several sets of workers. ${ }^{1-4,13}$ It has been found that the melting and glass transition temperatures first decrease with increasing side-chain length, go through a minimum, and then increase gradually with increasing side chain length for the highest members studied. The minimum in the series varies somewhat from report to report.

It has been claimed recently that poly(1-octene) has been crystallized for the first time. ${ }^{18}$ However, Table II indicates that melting points for this polymer have been reported in two earlier studies. However, the temperatures reported are disparate $\left(+20\right.$ and $\left.-38^{\circ} \mathrm{C}\right)$, with the latter possibly a glass temperature and certainly inconsistent with the subsequent report of poly(1-octene) crystallization at $-20^{\circ} \mathrm{C}^{18}$ An early report indicated that this polymer did not crystallize down to $-40^{\circ} \mathrm{C}$. $^{5}$

The crystalline forms of several isotactic poly(1olefin)s [poly(1-butene), ${ }^{15}$ poly(1-pentene),$^{16}$ and from poly(1-hexene) to the C-22 isotactic poly(1olefin) $]^{5,17}$ have been investigated by $\mathrm{X}$-ray studies. Thus, Turner-Jones found two crystalline forms in poly(1-tetradecene), poly(1-hexadecene), and poly(1-octadecene). For these higher members, two melting points have also been reported in several works. $^{1,6,7,17}$ Takayanagi $^{8-12}$ investigated the viscoelastic properties and crystal transformations of several poly(1-olefin)s and discussed in detail 
the effect of chemical structure on these properties. Plate and Shibaev ${ }^{19}$ have reported the structure and properties of comb-like polymers including the series of poly ( $n$-alkyl acrylates), poly(n-alkyl methacrylate)s, and the poly(1-olefin)s.

Mark and Flory have published the unperturbed dimension of poly(1-butene) and poly(1-pentene).$^{20}$ For higher poly(1-olefin)s, Shirayama, et al., ${ }^{21}$ have given the unperturbed dimension of poly(1-octene) and poly(1-octadecene). For other higher members, no information on chain dimensions has been reported so far.

The purpose of the present work is to examine the absolute values and trends for the melting transitions, specific volumes, and volume expansion and molecular conformation characteristics for the poly(1-olefin)s. The relationships obtained from this work may thus lead to a better understanding of the effects of polymer structures on physical properties.

The samples studied included poly(1-butene), poly(1-pentene), poly(1-hexene), poly(1-heptene), poly(1-octene), poly(1-nonene), poly(1-decene), poly(1-undecene), poly(1-dodecene), poly(1-tridecene), poly(1-hexadecene), and poly(1-octadecene). One sample of each polymer was generally available. Three samples of poly(1-octadecene) which differed in molecular weight and distribution were used.

\section{EXPERIMENTAL}

\section{Sample Preparation}

Most of the polymerizations were carried out in the following manner: a 300-m $l$ four-necked flask equipped with stirrer, reflux condenser, thermometer, and addition funnel was used. The flask was equipped with heating mantle, cooling bath, or neither, depending upon the temperature of polymerization. The flask assembly was dried for at least one hour in an oven at $135^{\circ} \mathrm{C}$ before use.

The flask was then charged with $100 \mathrm{~m} l$ of heptane followed by the required amount of titanium tetrachloride and aluminum triisobutyl. After an aging period of $10-30 \mathrm{~min}$, the olefin (25$50 \mathrm{~g}$ ) was added, usually at the predetermined temperature of polymerization. The time of polymerization varied from $1-24 \mathrm{hr}$, depending on olefin reactivity.
At the end of the polymerization period, the slurry was cooled or warmed to room temperature and treated with $100 \mathrm{ml}$ of either 2-propanol or 50:50 methanol-2-propanol. The polymer was slurried several times with fresh alcohol and usually treated for $2-3 \mathrm{hr}$ on the steam bath with additional alcohol. The polymer was frequently further purified by solution in hot hexane followed by reprecipitation with excess alcohol. The resulting polymer, after partial air drying, was dried in a vacuum oven at a temperature dependent upon the melting point of the polymer.

Due to the solubility of these polymers in hydrocarbon solvents, the atactic fractions usually could not be separated by extraction. In order to obtain the maximum degree of stereoregularity in each polymer, two techniques were employed. In some cases, lower polymerization temperatures were employed $\left(-78^{\circ} \mathrm{C}\right.$ to $\left.+25^{\circ} \mathrm{C}\right)$, and, in other cases, catalyst systems were used which gave more stereoregular polymers. The stereoregular polymers are believed to be isotactic by this polymerization. These polymers were polymerized by Avisun Corporation, Marcus Hook, Pennsylvania.*

Determination of Molecular Weight and Distribution

The molecular weights and distributions for the poly(1-olefin)s were obtained by using a Waters Associates Gel Permeation Chromatograph (GPC Model 200). 1, 2, 4-trichlorobenzene was used as the elution solvent. To prevent degradation and to simplify the measurement of the corresponding intrinsic viscosities, the operating temperature was chosen to be $80^{\circ} \mathrm{C}$. All samples were completely dissolved in this solvent at this temperature. The universal calibration was used to calculate the molecular weights and distributions. The details of this procedure have been described elsewhere. ${ }^{22,22_{\mathrm{a}}}$ The samples studied, along with their molecular weights and distributions, are listed in Table I.

\section{Determination of Melting Point, Specific Volume, and Volume Expansion Coefficient}

The melting points of the poly(1-olefin)s were determined by dilatometry and Differential Scanning Calorimetry (Perkin-Elmer DSC-1B). The specific volume at $27^{\circ} \mathrm{C}$ was determined by a density

* Now part of Amoco Chemicals Corporation, Naperville, Illinois. 
Table I. Poly(1-olefin) molecular weight and molecular weight distribution by calibrated gel-permeation chromatography

\begin{tabular}{lccc}
\hline \multicolumn{1}{c}{ Polymer } & $M_{n}$ & $M_{w}$ & $M_{w} / M_{n}$ \\
\hline Poly(1-butene) & $6.3 \times 10^{4}$ & $8.5 \times 10^{5}$ & 13.5 \\
Poly(1-hexene) & $4.0 \times 10^{3}$ & $1.7 \times 10^{4}$ & 4.3 \\
Poly(1-heptene) & $8.7 \times 10^{3}$ & $5.9 \times 10^{4}$ & 6.8 \\
Poly(1-octene) & $1.1 \times 10^{4}$ & $8.0 \times 10^{4}$ & 7.3 \\
Poly(1-nonene) & $6.8 \times 10^{4}$ & $3.7 \times 10^{5}$ & 5.4 \\
Poly(1-undecene) & $3.8 \times 10^{5}$ & $1.2 \times 10^{8}$ & 11.0 \\
Poly(1-hexadecene) & $3.4 \times 10^{5}$ & $2.5 \times 10^{8}$ & 7.4 \\
Poly(1-octadecene) & & & \\
$\quad$ Sample 1 & $7.3 \times 10^{5}$ & $3.5 \times 10^{6}$ & 4.8 \\
$\quad$ Sample 2 & $2.1 \times 10^{5}$ & $3.5 \times 10^{8}$ & 13.0 \\
$\quad$ Sample 3 & $6.9 \times 10^{4}$ & $4.3 \times 10^{5}$ & 6.2 \\
\hline
\end{tabular}

gradient column. The specific volume at other temperatures was measured by dilatometry. The volume expansion coefficient was calculated from specific volumes at different temperatures.

The polymers examined by dilatometry were poly(1-butene), poly(1-hexene), poly(1-heptene), poly(1-nonene), poly(1-undecene), poly(1-tridecene), and poly(1-octadecene), Sample 1. The other poly(1-olefin)s were measured exclusively by DSC, due to the small amounts available.

The dilatometer construction was according to Wood and Bekkedahl. ${ }^{23}$ The dilatometers were made of Pyrex glass and consisted of a bulb sealed to a capillary tube. The capillaries were precisionbore tubing of inside diameter $1 \mathrm{~mm}$. The tubes were calibrated by partial filling with mercury, observing the length, and by weighing. Dilatometers, containing $1.5-2.0 \mathrm{~g}$ of polymer, were evaculated for $5-6 \mathrm{hr}$ prior to test. The vacuum reached was $<10^{-3} \mathrm{mmHg}$. Mercury was then admitted to the evaculated system, through a twoway stopcock, until it filled the dilatometer bulb and stood at a suitable height in the capillary, with weighing before and after the addition of mercury. The dilatometers were placed in a stirred temperature bath and heated from ambient at a rate of about $0.2^{\circ} \mathrm{C} / \mathrm{min}$. Norman Weeks, a graduate student at the University of Massachusetts, obtained the corresponding equilibrium values from data at lower heating rates. For poly(1-butene), the equilibrium transition temperatures and volumes were compared with the values at a heating rate of $0.2^{\circ} \mathrm{C} / \mathrm{min}$. It was found that the equili- brium melting point was $1.5^{\circ} \mathrm{C}$ lower than the value at a heating rate of $0.2^{\circ} \mathrm{C} / \mathrm{min}$ but the expansion coefficients above the melting point were identical.

The DSC was calibrated by using standard samples of Indium and $p$-nitrotoluene. The peak of the DSC thermogram was taken as the melting point. For the poly(1-olefin)s, insufficient information was available on unit cell dimensions, melting point depression, and on heats of fusion to warrant estimates of percent crystallinity or heats of fusion. The samples in the DSC were precooled by liquid nitrogen down to $-100^{\circ} \mathrm{C}$ and then heated at a rate of $5^{\circ} \mathrm{C} / \mathrm{min}$.

\section{Measurements of Intrinsic Viscosity}

Cannon-Ubbelohde dilution viscometers were used. Capillary dimensions were chosen so that kinetic energy correlations for effux times were negligible. Efflux times, reproducible to $\pm 0.05 \%$ were obtained for the solvent and for each solution. Approximately $0.1 \%$ by weight of antioxidant was added to the solutions of poly(1-olefin) to inhibit oxidative degradation. The viscosities were measured in an oil bath which was controlled to $0.01^{\circ} \mathrm{C}$.

\section{RESULTS AND DISCUSSION}

The samples poly(1-hexene), poly(1-heptene), poly(1-octene), poly(1-nonene), and poly(1-undecene), were amorphous as prepared. ${ }^{24}$ Attempts were made to crystallize these polymers by cooling them from room temperature to $0^{\circ} \mathrm{C}$ by ice over $12 \mathrm{hr}$. By this treatment, poly(1-nonene) and poly(1-undecene) became markedly crystalline and poly(1-heptene) somewhat so, as observed from the volume change for melting. The poly(1-hexene) and poly(1-octene) samples were not crystallizable by these techniques, with no melting point features observed by either dilatometry or DSC. The specific volume $v s$. temperature from dilatometry is plotted in Figures 1 and 2 for the samples of poly(1-hexene), poly(1-heptene), poly(1-nonene), poly(1-undecene), poly(1-tridecene), and poly(1octadecene).

For the higher members, two melting transitions were found. (See Table II.) These dilatometric melting features are shown in Figure 2 for poly(1tridecene) and poly(1-octadecene) (Sample 1). Figures $3-5$ show the corresponding two melting 
points of poly(1-tridecene), poly(1-hexadecene), and poly(1-octadecene) (Sample 1) from DSC measurements. The other two poly(1-octadecene)

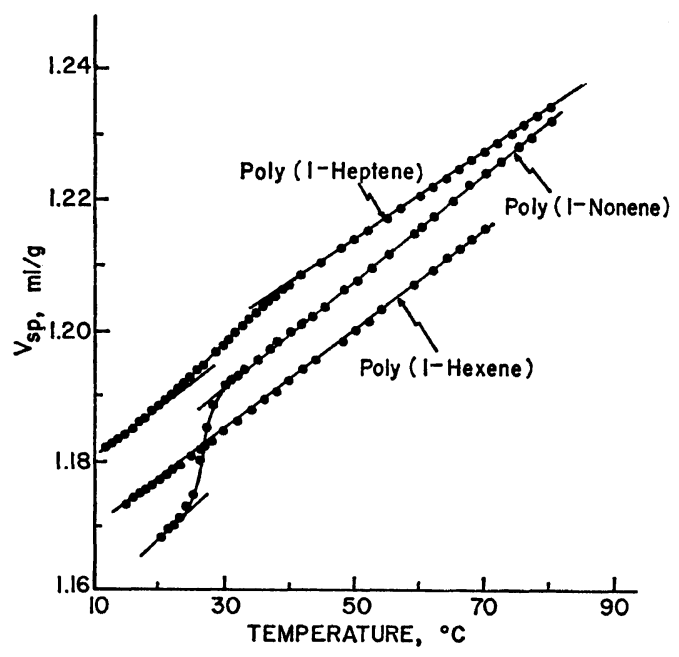

Figure 1. The specific volume vs. temperature for poly(1-hexene), poly(1-heptene), and poly(1-nonene).

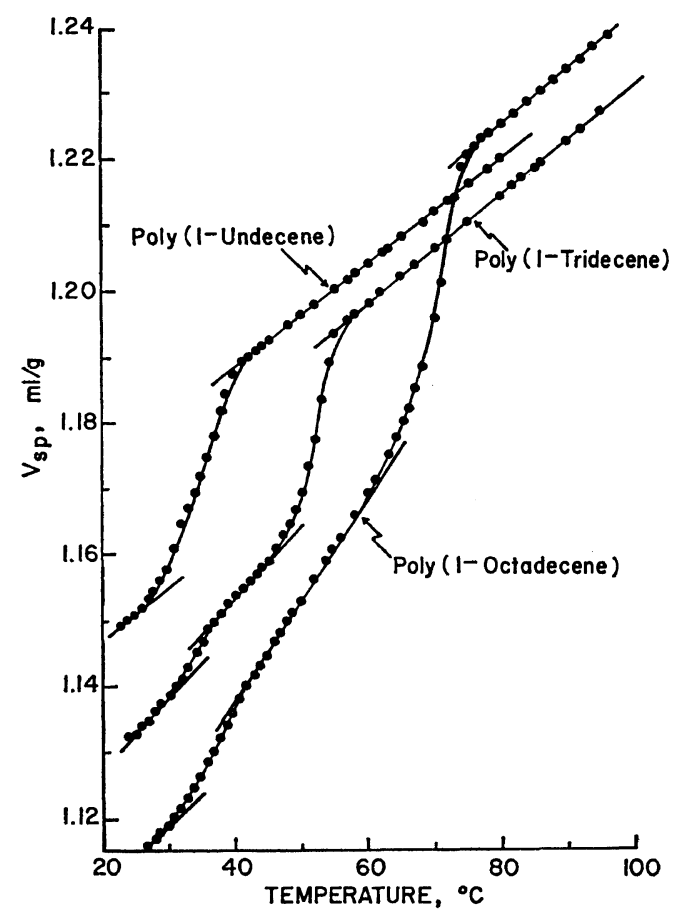

Figure 2. The specific volume vs. temperature for poly(1-undecene), poly(1-tridecene), and poly(1-octadecene). samples also show two melting points. They have the same lower melting point $\left(42^{\circ} \mathrm{C}\right)$ as poly $(1-$ octadecene) (Sample 1). For the higher melting point, $74^{\circ} \mathrm{C}$ was found, for poly(1-octadecene), Samples 1, 2, and $68^{\circ} \mathrm{C}$ for sample 3. On rapid cooling of the melt in liquid nitrogen, the C-13 and higher poly(1-olefin)s have been shown on subsequent heating to exhibit two endotherms separated by an exotherm. The latter is reportedly the result of a quenching of the higher melting side chain crystallization. ${ }^{17}$ We conclude that side chain crystallization occurs at least by poly(1tridecene), but also possibly for lower members of the series, $\mathrm{C}-10$ to $\mathrm{C}-12$, where side and main chain

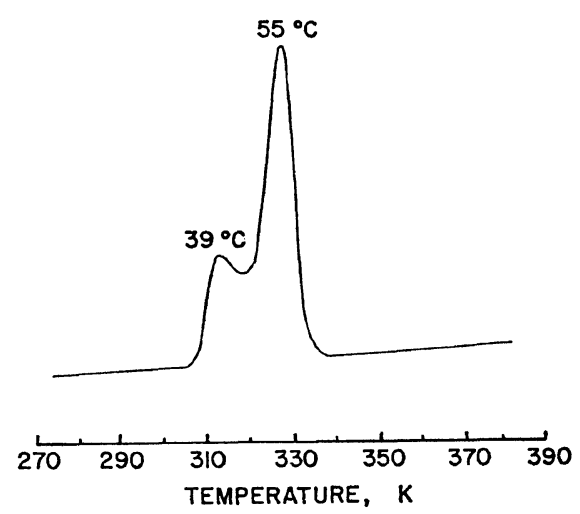

Figure 3. The DSC thermogram of poly(1-tridecene).

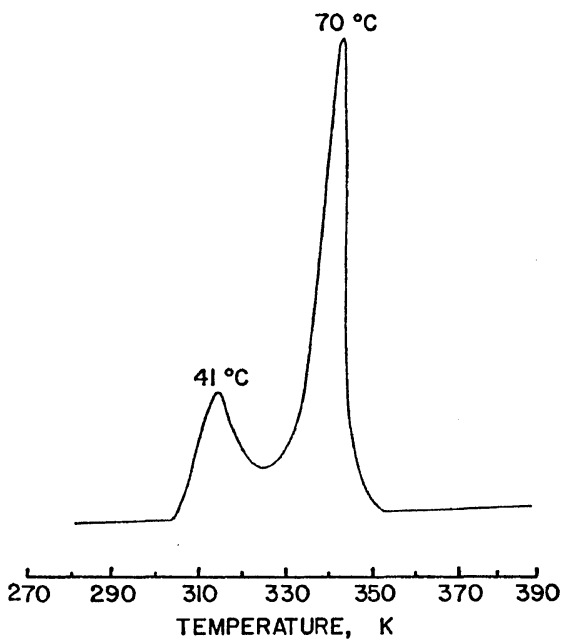

Figure 4. The DSC thermogram of poly(1-hexadecene). 
Physical Properties of the Poly(1-olefin)s

Table II. The melting points of poly(1-olefin)s

\begin{tabular}{|c|c|c|c|c|c|c|c|}
\hline \multirow{2}{*}{ Poly(1-olefin)s } & \multicolumn{2}{|c|}{ This work, ${ }^{\circ} \mathrm{C}$} & \multicolumn{5}{|c|}{ Literature, ${ }^{\circ} \mathrm{C}$} \\
\hline & Dilatometer & $\mathrm{DSC}$ & ref 1 & ref 2 & ref 3 & ref 13,14 & ref 17 \\
\hline Poly(1-butene) & 128 & 126 & - & 132 & 120 & 125 & - \\
\hline Poly(1-pentene) & - & 70 & - & 80 & 70 & 73 & - \\
\hline Poly(1-hexene) & - & - & - & - & -55 & - & - \\
\hline Poly(1-heptene) & 38 & 37 & - & 17 & -40 & - & 一 \\
\hline Poly(1-octene) & - & 一 & 20 & - & -38 & - & - \\
\hline Poly(1-nonene) & 30 & 32 & 29 & 19 & - & - & - \\
\hline Poly(1-decene) & - & 35 & 32 & 34 & - & 29 & - \\
\hline Poly(1-undecene) & 40 & 39 & 41 & - & - & - & - \\
\hline Poly(1-dodecene) & - & 44 & 47 & 49 & 45 & 46 & - \\
\hline \multirow[t]{2}{*}{ Poly(1-tridecene) } & 55 & 55 & 55 & - & - & 52 & - \\
\hline & 39 & 39 & - & - & - & - & - \\
\hline \multirow[t]{2}{*}{ Poly(1-tetradecene) } & - & - & - & - & - & - & 54 \\
\hline & - & - & - & - & - & - & 3 \\
\hline \multirow[t]{2}{*}{ Poly(1-pentadecene) } & - & - & - & - & - & - & 59 \\
\hline & - & 一 & - & - & - & - & 13 \\
\hline \multirow[t]{2}{*}{ Poly(1-hexadecene) } & - & 70 & 67 & 67.5 & - & 63 & 63 \\
\hline & - & 41 & 32 & - & - & - & 28 \\
\hline \multicolumn{8}{|l|}{ Poly(1-octadecene) } \\
\hline \multirow[t]{2}{*}{ Sample 1} & 75 & 74 & 75 & - & - & 71 & - \\
\hline & 42 & 42 & 43 & - & - & 43 & - \\
\hline \multirow[t]{2}{*}{ Sample 2} & - & 74 & - & - & - & - & - \\
\hline & - & 42 & - & - & - & - & - \\
\hline \multirow[t]{2}{*}{ Sample 3} & - & 68 & - & - & - & - & - \\
\hline & - & 42 & - & - & - & - & - \\
\hline
\end{tabular}

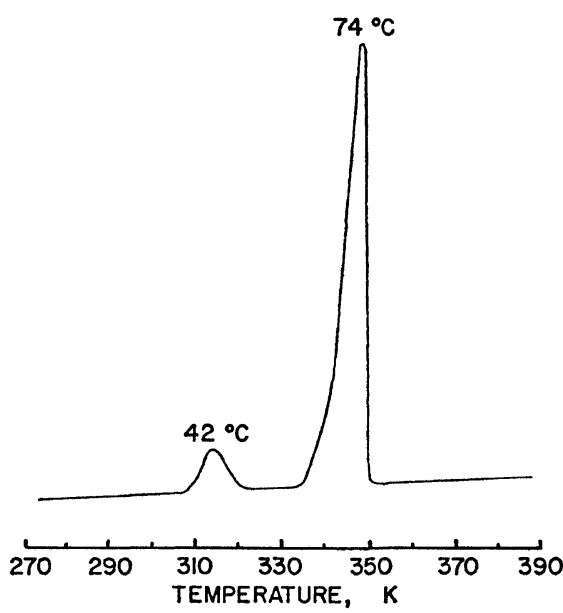

Figure 5. The DSC thermogram of poly(1-octadecene), Sample 1.

melting may merge. The feature of side chain crystallization was independently assumed to start only at poly(1-tetradecene). ${ }^{17}$ When the higher members of poly(1-olefin) series were cooled from the melt to $0^{\circ} \mathrm{C}$ at $20^{\circ} \mathrm{C} / \mathrm{min}$, then the lower melting point disappeared and only the higher melting point remained.

Aubrey and Barnatt ${ }^{6}$ showed that when poly(1octadecene) was extracted with hexane, the solventsoluble polymer had only the lower melting point and the solvent-insoluble fraction had the higher melting point. Similar results were found previously by using pentane as an extracting solvent. ${ }^{1}$ It was suggested that this phenomenon was due to two different species, such as atactic and isotactic polymer. However, if the atactic form can crystallize, the side chain rather than the main chain is involved in crystallization. ${ }^{1,6}$ More recently, X-ray data appear to confirm that for the higher isotactic poly(1-olefin)s, both the main chain (helical conformation) and the side chain (planar zig-zag) can crystallize, with the latter corresponding to the transition at higher temperature. ${ }^{17}$ If this be the case, the lower melting endotherms in this and prior $^{17}$ work are inexplicably small considering 
mole ratios, percent crystallinities, and heats of fusion. For the two melting peaks in the higher poly(1-olefin)s, the lower melting transition heat is much smaller than the higher. This contrasts with results of Aubrey and Barnatt ${ }^{6}$ and with Daniels, et $a l^{6}{ }^{6}$ Their samples show a larger peak for the lower melting form than for the higher.

The specific volumes of poly(1-olefin)s are compared at a series of temperatures in Figure 6 . The values correspond to trends in chain-to-chain packing. It may be seen that the density becomes less and less with increasing monomer size until it hits a minimum at around poly(1-hexene) to poly(1-heptene). The densities then increase slightly with increasing side-chain length, leveling off for the higher members of the series. The pronounced density increase shown in Figure 6 for the lowest three members is due in part to crystallinity. Measured specific volumes at $27^{\circ} \mathrm{C}$ may be compared in Figure 6 with values calculated at the same temperature for the idealized corresponding crystal. $^{32}$ The same trend of volumes with composition may be noted for both the semi-crystalline and pure crystalline components. Estimates of purely amorphous volumes are given in Table III. Values in the compositional series available from the survey by van Krevelen ${ }^{32}$ are compared with those obtained here by extrapolating densities in the amorphous region down to $27^{\circ} \mathrm{C}$. Where comparable data are available, there are clear

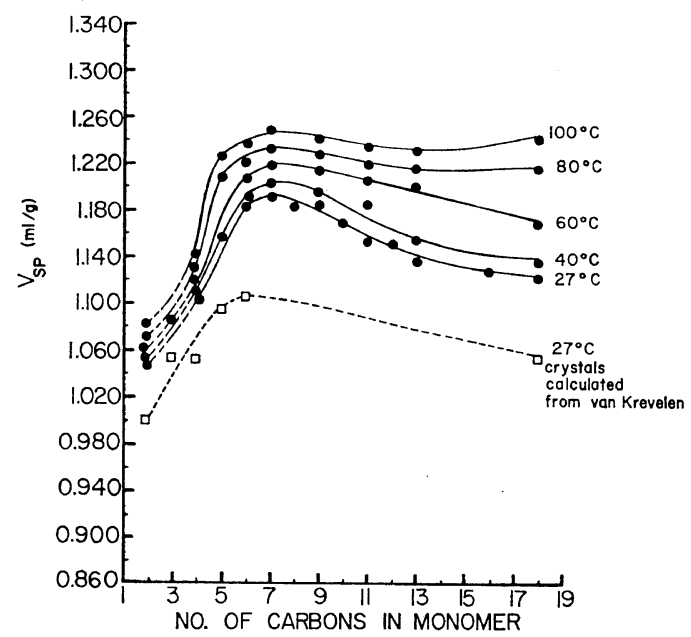

Figure 6. Measured specific volumes of poly(1olefin)s. discrepancies but no clear trend with composition. The values, of course, involve extensive extrapolation as a source of error. The systematic trends, however, are interesting and clearly evident. Figure 6A shows a plot of amorphous volumes at $27^{\circ} \mathrm{C}$ for the poly(1-olefins) as available in the literature $^{32}$ and as obtained here by extrapolation from densities of the corresponding melt state. These values are correlated molar volumes calculated from van der Waals volumes. The agreement is

Table III. Values for amorphous specific volumes at $27^{\circ} \mathrm{C}$ by extrapolation to lower temperature from the melt state for poly(1-olefin)s

\begin{tabular}{lcc}
\hline \multirow{2}{*}{ Poly(1-olefin) } & \multicolumn{2}{c}{$\left(V_{\mathrm{sp}}\right), \mathrm{m} l / \mathrm{g}$} \\
\cline { 2 - 3 } & This study & $\begin{array}{c}\text { From } \\
\text { von Krevelen }\end{array}$ \\
\hline Ethylene & & 1.177 \\
Propylene & & 1.177 \\
Butene & 1.153 & 1.163 \\
Pentene & & 1.176 \\
Hexene & 1.182 & 1.163 \\
Heptene & 1.197 & \\
Nonene & 1.188 & \\
Undecene & 1.178 & \\
Tridecene & 1.172 & \\
Octadecene & 1.183 & 1.163 \\
\hline
\end{tabular}

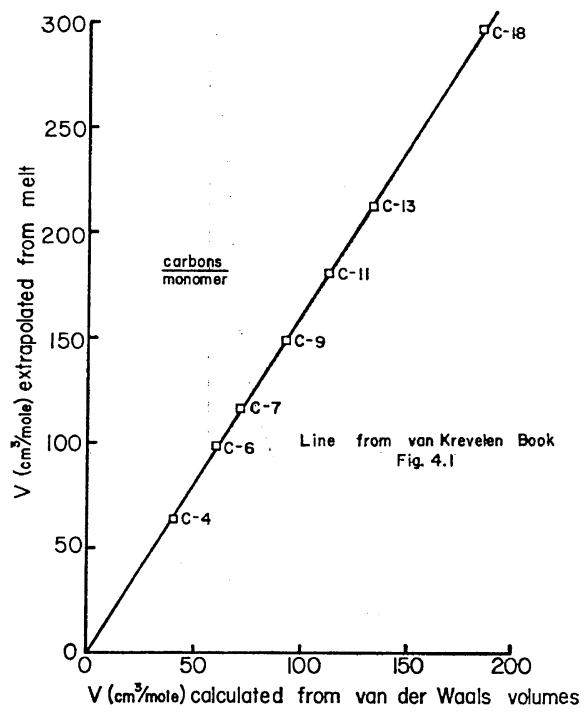

Figure 6A. Comparison of calculated and extrapolation of measured specific volumes for amorphous poly(1-olefin)s at $27^{\circ} \mathrm{C}$. 
seen to be excellent with the correlation extended to higher values than yet reported. ${ }^{32}$

Takayanagi has pointed out that, for a side chain of infinite length, the melting point should reach the melting point of high density polyethylene. ${ }^{12}$ The melting point of the higher poly(1-olefin), for which melting points increase with the length of side chain, can be plotted $v s .1 /(N+2)$, where $N$ is the number of carbons in the side chain. The plot can thus be extrapolated to infinite sidechain length. Data shown in Figure 7 confirm that the extrapolation of the higher melting points to infinite side-chain length reaches the melting point of high density polyethylene..$^{8-12}$ This is not the case for the extrapolation of the lower melting points, which suggested that the higher transition is associated with the side chain: see Figure 7. An alternate extrapolation of the lower transition data leads to $147^{\circ} \mathrm{C}$, which is better than $127^{\circ} \mathrm{C}$. We opt for lower melting being due to a side chain transition, with the higher melting due to combined side and main chain transition. The volume expansion above the melting point, $\alpha_{\mathrm{m}}$, in $\mathrm{m} l / \mathrm{g}^{\circ} \mathrm{C}$, was calculated from the slope of the plot of specific volume vs. temperature. Accordingly, the $\alpha_{\mathrm{m}}$ is also plotted $v s .1 /(N+2)$ : see Figure 8. Again the extrapolation reaches the value of $\alpha_{\mathrm{m}}$ for high density polyethylene. The melting point and $\alpha_{\mathrm{m}}$ data used were obtained from dilatometry in our laboratory.

According to X-ray, infrared, and Raman studies, ${ }^{5,18}$ the side chains for upper members of poly(1-olefin)s have almost the same structure as the main chain of polyethylene. This is thus

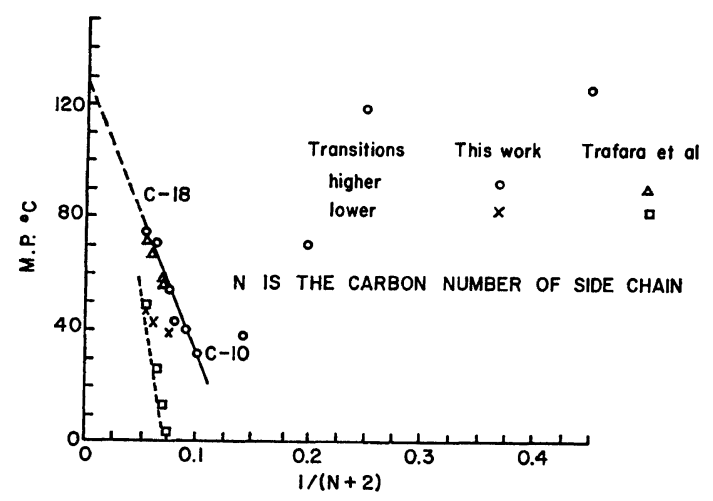

Figure 7. The transitions of poly-1-olefins $v s .1 /(N+$ 2). $\quad N$ is the number of side chain carbons.

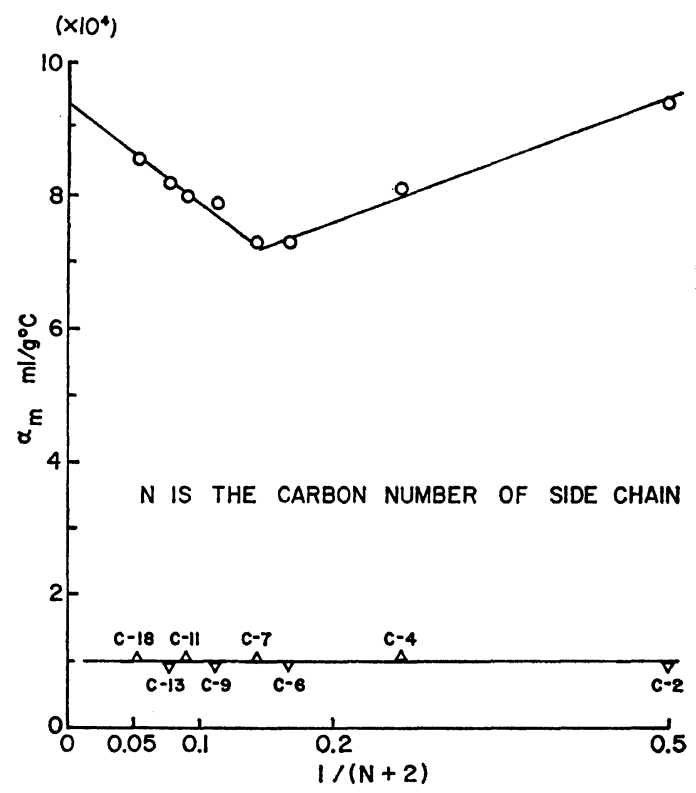

Figure 8. The volume expansion of poly(1-olefin) melts vs. $1 /(N+2)$.

consistent with the fact that the extrapolated melting point and expansion coefficient for infinite side-chain length have the same values as for polyethylene.

The minimum value of melting point and thermal expansion and the maximum in specific volume, which occurs around poly(1-hexene) to poly(1octene), can be explained by the packing state of the molecules and/or the conformation of the molecules. The conformation and packing of the molecules in the crystalline region have been presented for the poly(1-olefin) series. ${ }^{5,25,26}$ However, Takayanagi ${ }^{12}$ has shown that the conformation of molecules and the packing of molecular chains in the amorphous region or in the melt are not completely random but are similar to those in the crystalline region. This is consistent with other studies of poly(alkyl acrylates) and poly(alkyl methacrylates. ${ }^{19} \mathrm{He}$ found that the higher members, i.e., long side chains, show some order by X-ray diffraction well above the highest melting point, which he describes as a "polymer liquid crystal."27

As mentioned, the specific volumes for the poly(1-olefin) series, extrapolated from the melt state to absolute zero, have a maximum around poly(1- 
hexene) or poly(1-heptene). This may indicate the chain-to-chain packing density in the amorphous state is smallest in this region. Takayanagi, ${ }^{11}$ et al., have also shown that the packing state of poly(1-olefin) molecules becomes more open as the side-chain length increases from polypropylene to poly(1-octene) and that, as the side-chain length is made even longer, the packing of molecules bebecomes more dense. In our case, the changeover appears to be in the region of poly(1-hexene) and poly(1-octene).

\section{Unperturbed Chain Dimension}

The above discussions of molecular packing are based on the bulk properties for the poly(1-olefin)s. It is thus of interest to investigate changes in individual chain dimension with composition from intrinsic viscosities near a theta temperature. At theta conditions, molecules exhibit their unperturbed dimension, i.e., dimension determined by bond distances, bond angles, and the potentials for hindered bond rotation. ${ }^{28}$

The theta temperature, $T_{\theta}$, can be considered the incipient immiscibility temperature for polymer molecules of infinite molecular weight. It has been shown from thermodynamic considerations that for dilute polymer solutions at $T_{\theta}$ the second virial coefficient, $A_{2}$, is zero and higher coefficients are near zero. ${ }^{28}$ Therefore one must either measure the second virial coefficient, $A_{2}$, at several temperatures and find $T_{\theta}$ by interpolation or extrapolation to $A_{2}=0$, or determine the $T_{0}$ by extrapolating the critical miscibility temperature of a polymersolvent system to infinite molecular weight. Neither method is available for the poly(1-olefin)s because of limited sample sizes. In this method, the precipitation temperature is determined as a function of volume concentration at very low concentration. The reciprocal of the absolute precipitation temperature is plotted $v s$. the $\log$ of the volume fraction of polymer. The concentrations employed were generally from volume fraction $10^{-1}$ to $10^{-3}$; the resulting line was extrapolated to a polymer volume fraction of one and this value taken as the theta temperature. ${ }^{29}$ An advantage of this method is the need for only one molecular weight for each polymer. To check the accuracy of the method, poly(1-butene) was tested first. The $T_{\theta}$ measured in anisole is compared in Figure 9 with the literature value by Krigbaum, et $a l^{30}$
At very low concentration, the reciprocal of precipitation temperature as a function of polymer volume fraction is linear. The temperature obtained from extrapolation to pure polymer is $88 \pm$ $1^{\circ} \mathrm{C}$. This is close to the $T_{\theta}\left(89.1^{\circ} \mathrm{C}\right)$ for consolute temperatures as a function of isotactic molecular weights given by Krigbaum, et al. ${ }^{30}$ The method ${ }^{29}$ therefore seems to be a convenient way, with a precision of about 1 to $2^{\circ} \mathrm{C}$, for locating $T_{\theta}$. The $T_{\theta}$ for the poly(1-olefin)s was measured in two solvents, anisole and cyclohexanone. (See Figure 10.) This method is recognized as approximate ${ }^{29}$ and likely is influenced by molecular weight distribution, yet it provides qualitative values for just this case where only a single molecular weight

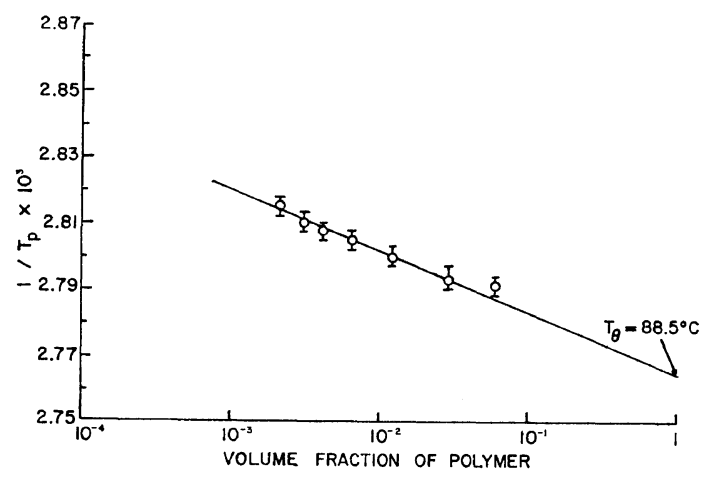

Figure 9. Theta temperature of poly(1-butene) from Cornet's method.

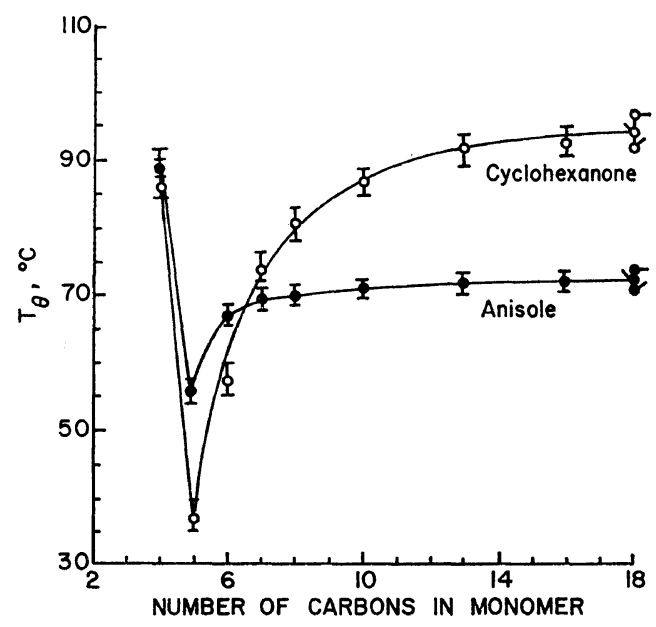

Figure 10. Theta temperature of poly(1-olefin) series in anisole and in cyclohexanone. 
is available for most compositions. If additional samples had been available, a study at several concentrations would have been desirable in order to check whether the second virial coefficient was in fact zero and to determine the exact dependence on molecular weight. ${ }^{33}$ The results in different solvents show a common minimum at poly(1pentene). The sequence of three poly(1-octadecene) samples have a $T_{\theta}$ at 70,73 , and $71^{\circ} \mathrm{C}$ in anisole and 94,97 , and $92^{\circ} \mathrm{C}$ in cyclohexanone, respectively. The temperature coefficient of $[\eta]$ for poly(1-olefin)s, in the vicinity a bove $T_{\theta}$, is only $+1 \% /{ }^{\circ} \mathrm{C}$ from $70-90^{\circ} \mathrm{C}$. This is shown in Figure 11. Therefore, any small error in $T_{\theta}$ introduced by the test method is not of importance in the determination of $[\eta]$ at $T_{\theta}$.

The unperturbed mean-square end-to-end distance $\left\langle\boldsymbol{R}_{0}{ }^{2}\right\rangle$ is obtained from the measurements of intrinsic viscosity $[\eta]_{\theta}$ at theta condition. $[\eta]_{\mathrm{u}}$ is related to $\left\langle R_{0}{ }^{2}\right\rangle$ by the following equation:

$$
[\eta]_{\theta}=\Phi\left[\frac{\left\langle R_{0}{ }^{2}\right\rangle^{3 / 2}}{M}\right] M^{1 / 2}=K M^{1 / 2}
$$

Here $\Phi$ is the universal constant of theoretical value $2.87 \times 10^{21}$ for $[\eta]$ in $\mathrm{d} l / \mathrm{g}$ and $M$ is the polymer molecular weight. Weight average molecular weight was used here for the calculation. The values of $\left\langle R_{0}{ }^{2}\right\rangle^{1 / 2} / M^{1 / 2}$ calculated in this way are shown in Table IV. The values found in the literature are also listed in the table. The data show a small increase in chain dimensions from poly(1butene) to poly(1-hexene), then a decrease with increasing side-chain length. The apparent decrease

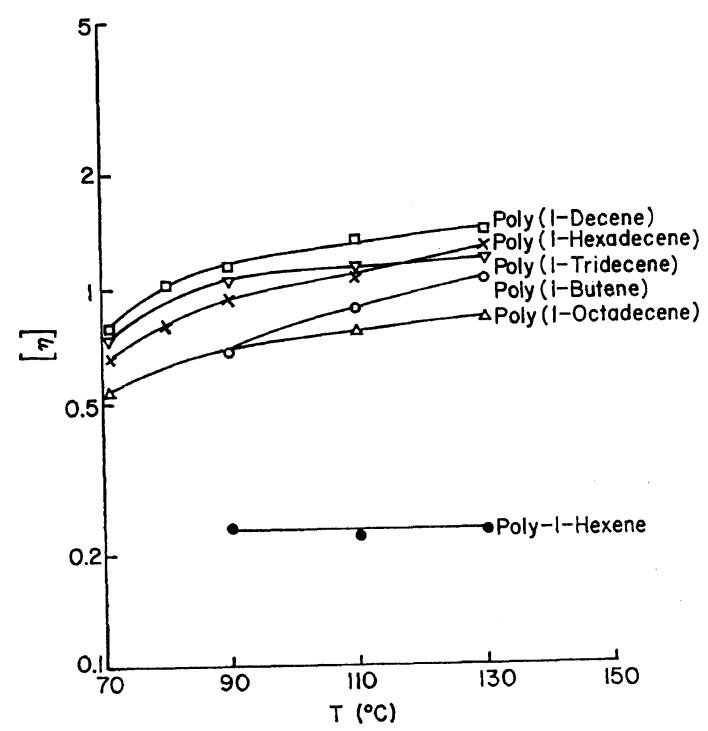

Figure 11. Intrinsic viscosity of poly(1-olefin)s in anisole $v s$. temperature.

in size for the higher members of the series is due in part to a decrease in chain length with increasing side-chain length for comparisons at constant molecular weight. This effect can be eliminated by calculation of the characteristic ratio, $\left\langle R_{0}{ }^{2}\right\rangle \mid n l^{2}$, which is normalized to main chain length $n$. The bond length, $l$, for all members must be very similar and near $1.54 \AA$. The calculated values of $\left\langle R_{0}{ }^{2}\right\rangle /$ $n l^{2}$ are shown in Table IV along with available literature data. It is obvious that the characteristic ratio for the poly(1-olefin) series monotonically

Table IV. Unperturbed chain dimension, $\left\langle R_{0}^{2}\right\rangle^{1 / 2} / M^{1 / 2}$, characteristic ratio, $\left\langle\boldsymbol{R}_{0}{ }^{2}\right\rangle / n l^{2}$, and steric factor, $\sigma$, for the poly(1-olefin)s

\begin{tabular}{ccccc}
\hline Polymer & $\left\langle R_{0}{ }^{2}\right\rangle^{1 / 2} / M^{1 / 2} \times 10^{11}$ & $\left\langle R_{0}{ }^{2}\right\rangle / n l^{2}$ & $\sigma$ & Reference \\
\hline Poly(1-butene) & 721 & 6.2 & 1.73 & $\mathrm{a}$ \\
& 775 & & 1.86 & 32 \\
Isotactic & 1130 & & 2.70 & 30 \\
Atactic & 1000 & & 2.40 & 30 \\
Poly(1-pentene) & 785 & 9.2 & 2.10 & 20 \\
Poly(1-hexene) & 861 & 13.0 & 2.55 & $\mathrm{a}$ \\
Poly(1-octene) & $690-800$ & & $2.36-2.74$ & 21 \\
Poly(1-decene) & 697 & 14.0 & 2.64 & $\mathrm{a}$ \\
Poly(1-tridecene) & 638 & 15.5 & 2.78 & $\mathrm{a}$ \\
Poly(1-octadecene) & & & & $\mathrm{a}$ \\
Sample 1 & 584 & 18.3 & 3.0 & $\mathrm{a}$ \\
Sample 2 & 610 & 19.6 & 3.12 & \\
\hline
\end{tabular}

a This work. 
increases with increasing side-chain length.

The steric factor, $\sigma$, is defined by eq 31 :

$$
\sigma=\left[\left\langle R_{0}{ }^{2}\right\rangle\left\langle\left\langle R_{0}{ }^{2}\right\rangle_{\mathrm{f}}\right]^{1 / 2}\right.
$$

where $\left\langle R_{0}{ }^{2}\right\rangle_{\mathrm{r}}$ is the theoretical mean square endto-end distance for free rotation. The values of $\sigma$ of the poly(1-olefin)s are listed in Table IV. They also systematically increase with increasing side-chain length. Differences between the workers cited in Table IV may be due to (1) the different values of $\Phi$ used in the calculation, (2) different tacticities in samples, and (3) effects of molecular weight distribution.

The purpose of our work is to compare the chain dimensions for the poly(1-olefin)s at similar conditions in order to determine the change in dimensions with composition. Although the samples of poly(1-octadecene) have different unperturbed dimensions, the differences do not affect the observed trend with composition.

Acknowledgment. The authors would like to express appreciation to Professor Julian Johnson for helpful discussions of theta temperature experiments.

\section{REFERENCES}

1. D. L. Beck, J. R. Knox, and J. A. Price, presented before Division of Petroleum Chemistry, ACS Meeting, March 31-April 4, 1963.

2. K. J. Clark, A. Turner-Jones, and D. J. H. Sandiford, Chem. Ind. (London), 2010 (1962).

3. F. P. Reding, J. Polym. Sci., 21, 547 (1956).

4. M. S. Dannis, J. Appl. Polym. Sci., 1, 121 (1959).

5. A. Turner-Jones, Makromol. Chem., 71, 1 (1964).

6. D. W. Aubrey and A. Barnatt, J. Polym. Sci., Part $A-2,6,241$ (1968).

7. C. A. Daniels, S. H. Maron, and P. J. Livesey, $J$. Macromol. Sci.-Phys., B4, 47 (1970).

8. S. Manabe and M. Takayanagi, Kogyo Kagaku Zasshi, 73, 1572 (1970).

9. S. Manabe, S. Minami, and M. Takayanagi, Kogyo Kagaku Zasshi, 73, 1577 (1970).

10. S. Manabe and M. Takayanagi, Kogyo Kagaku Zasshi, 73, 1581 (1970).

11. S. Manabe, S. Nakamura, S. Uemura, and M. Takayanagi, Kogyo Kagaku Zasshi, 73, 1587 (1970)
12. S. Manabe and M. Takayanagi, Kogyo Kagaku Zasshi, 73, 1595 (1970).

13. W. Philippoff and E. G. M. Torngvist, J. Polym. Sci., Part C, 23, 881 (1968).

14. E. G. M. Torngvist, Ann. N. Y. Acad. Sci., 155, 447 (1969).

15. C. D. Armeniades and E. Baer, J. Macromol. Sci. (Phys.), B1 (2), 309 (1967).

16. M. Moser and M. Boudeulle. J. Polym. Sci., Polym. Phys. Ed., 14, 1161 (1976).

17. G. Trafara, R. Koch, K. Blum, and D. Hummel, Makromol. Chem., 177, 1089 (1976).

18a. K. Holland-Moritz, P. Djudovic, and D. O. Hummel, Prog. Colloid Polym. Sci., 57, 206 (1975).

18b. K. Holland-Moritz, I. Modric, K.-U. Heinen, and D. O. Hummel, Kolloid Z.-Z. Polym., 251, 913 (1973).

19a. N. A. Plate and V. P. Shibaev, Vysokomol. Soedin, Ser. $A, 13,410$ (1971).

19b. N. A. Plate and V. P. Shibaev, J. Polym. Sci., Macromol. Rev., 8, 117 (1974).

20. J. E. Mark and P. J. Flory, J. Am. Chem. Soc., 87, 1423 (1965).

21. K. Shirayama, T. Matsuda, and S. I. Kita, Makromol. Chem., 147, 157 (1971).

22. J. V. Dawkins and J. W. Maddock, Eur. Polym. J. 7, 1537 (1971).

22a. S. Mori, J. Appl. Polym. Sci., 18, 2391 (1974).

23. L. A. Wood and N. Bekkedahl, J. Res. Natl. Bur. Stand., 36, 489 (1946).

24. J. S. Wang, R. S. Porter, and J. R. Knox, J. Polym. Sci., Part B, 8, 671 (1970).

25. G. Natta and P. Corradini, Makromol. Chem., 16, 213 (1955).

26. G. Natta, P. Corradini, and I. W. Bassi, Makromol Chem., 21, 240 (1956).

27. N. A. Plate, Seminar at University of Massachusetts, 1971.

28. P. J. Flory, "Principles of Polymer Chemistry," Cornell University Press, Ithaca, New York, 1953.

29. C. F. Cornet and H. Van Ballegooijen, Polymer, 7, 293 (1966).

30. W. R. Krigbaum, J. E. Kurz, and P. Smith, J. Phys. Chem., 65, 1984 (1961).

31. M. Kurata and W. H. Stockmayer, Fortsch. Hochpolym. Forsch., 3, 196 (1963).

32. D. W. van Krevelen, "Properties of Polymers," Second Edition, Elsevier, New York, N. Y., 1976.

33. S. M. Aharoni, Macromolecules, 10, 1408 (1977). 